\title{
Use Cutting Enzymes to Encode the Secret Message
}

\section{Saadoun H. A.}

\section{College of Science}

\section{University of Al Mosul}

\section{Received on : 24/6/2013}

\section{Accepted on 12/2/2014}

\begin{abstract}
Researchers begin to explore new methods to manage the huge amount of data shared over the Internet, in order to use them more efficiently and safely, One of the ways that is raised nowadays is Steganography, The art of information hiding within electronic media. Steganography ways vary in their approaches for hiding information.

During this research designed algorithm that using restriction enzymes to cutting sequence of DNA, the fragments resulted was used to building symbols table (character , number, special character,...), by using symbols table the plain message (text ,sound ,image, video) coding to DNA and sent it to recipient, the recipient build symbols table same way in the sender site and use function to known restriction enzymes, using restriction enzymes to cutting secret sequence DNA, by using the fragments of DNA and symbols table can retrieve the plain message (text, sound, image, video).

Keyword: Algorithms , Enzymes , DNA

$$
\begin{aligned}
& \text { استخدام الانزيمات القاطعة لترميز الرسالة السرية } \\
& \text { سعدون حسين عبدالله } \\
& \text { كلية العلوم } \\
& \text { جامعة الموصل }
\end{aligned}
$$

201412112 : تاريخ قبول البحث

$2013 \backslash 6124:$ تاريخ استلام البحث

\section{الملخص}

اتجه الباحثون إلى استكثاف طرائق جديدة لإدارة الكم الهائل من البيانات المُشتركة عبر الانترنت من أجل

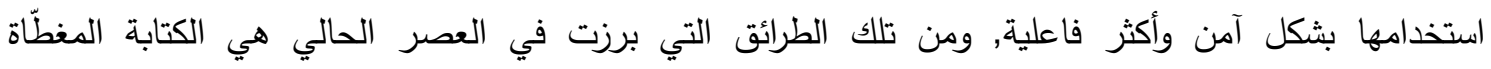
وهو فن إخفاء المعلومات ضمن وسط، تتفاوت طرائق الكتابة المغطّاة في نهجها لإخفاء المعلومات.

خلال هذا البحث تم تصميم خوارزمية تستخدم الانزيمات القاطعة بأنواعها المختلفة لقطع قطع محددة من

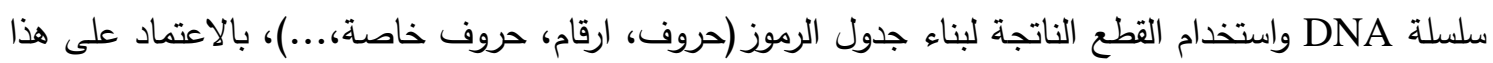

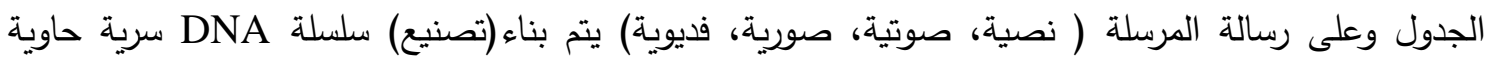
للرسالة السرية ، ترسل سلسلة الـ DNA الناتج الى المستلم وهو بدوره يعتمد على الخوارزمية السابقة لبناء الجدول

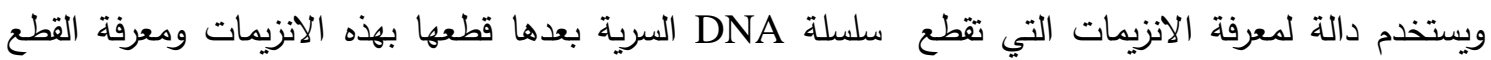

$$
\text { وبالاستعانة بجدول الرموز يتم استرجاع الرسالة السرية( نصية، صوتية ، صورية ، فديوية). }
$$

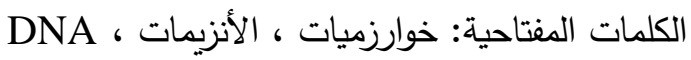




\section{Introduction مقدمة}

في عالمنا هذا ذي الرقمية العالية تلعب شبكة الانترنت دوراً مهماً في نقل البيانات وتبادلها ومع ذلك ولأنها شبكة عالمية ووسيط عام فإن بعض البيانات (وخاصةً السرية منها) قد تتعرض إلى السرقة, أو النسخ, أو التعديل,

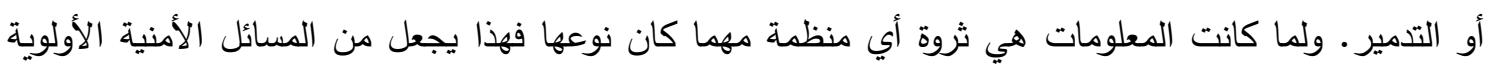

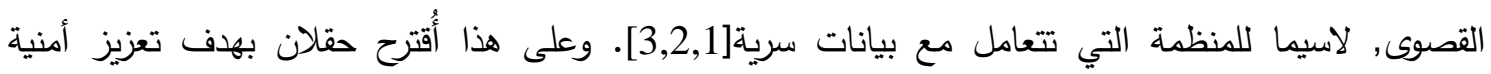
الاتصال: (التشفير Cryptography وإخفاء المعلومات Information/Data Hiding) وبالرغم من أن كليهما وجدا على حد سواء لحماية البيانات السرية فإن الفرق الأساسي بينهما هو في ظهور البيانات المنقولة[3].

Information Hiding إخفاء المعلومات

يعد أمن المعلومات اليوم احد أهم عوامل تكنولوجيا المعلومات والاتصالات. ووفقا لذلك فنحن بحاجة إلى

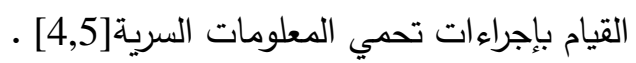

إن إخفاء المعلومات (أو إخفاء البيانات) هي واحدة من التقنيات المتجددة باستمرار التي تهدف إلى توفير

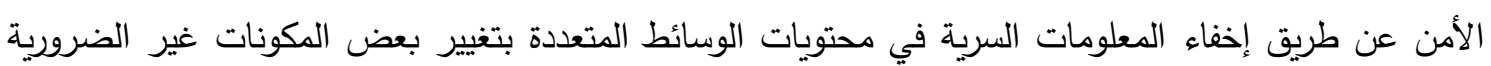
في الملف المضيف أو الملف الغطاء [7,6,5] • ومع تقبل المجتمع للتقنيات الرقمية لإرسال الرسائل واستقبالها على نطاق واسع, ظهرت الحاجة إلى تقنيات

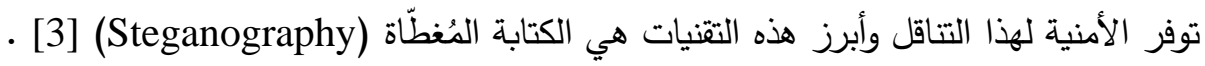
هناك أربعة عناصر في الإخفاء تمثل بالثكل (1) وهي كالآتي [9,8].

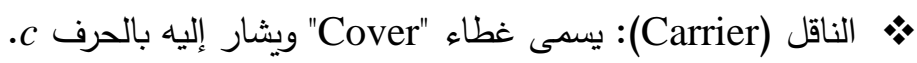

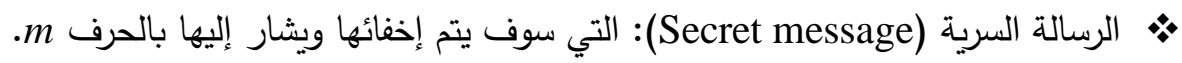
• مسط الإخفاء (Stego-media): هو إخراج الناتج بعد الإخفاء ويشار إليه بالحرف s. • مفتاح الإخفاء (Stego-key): ويشار إليه بالحرف k.

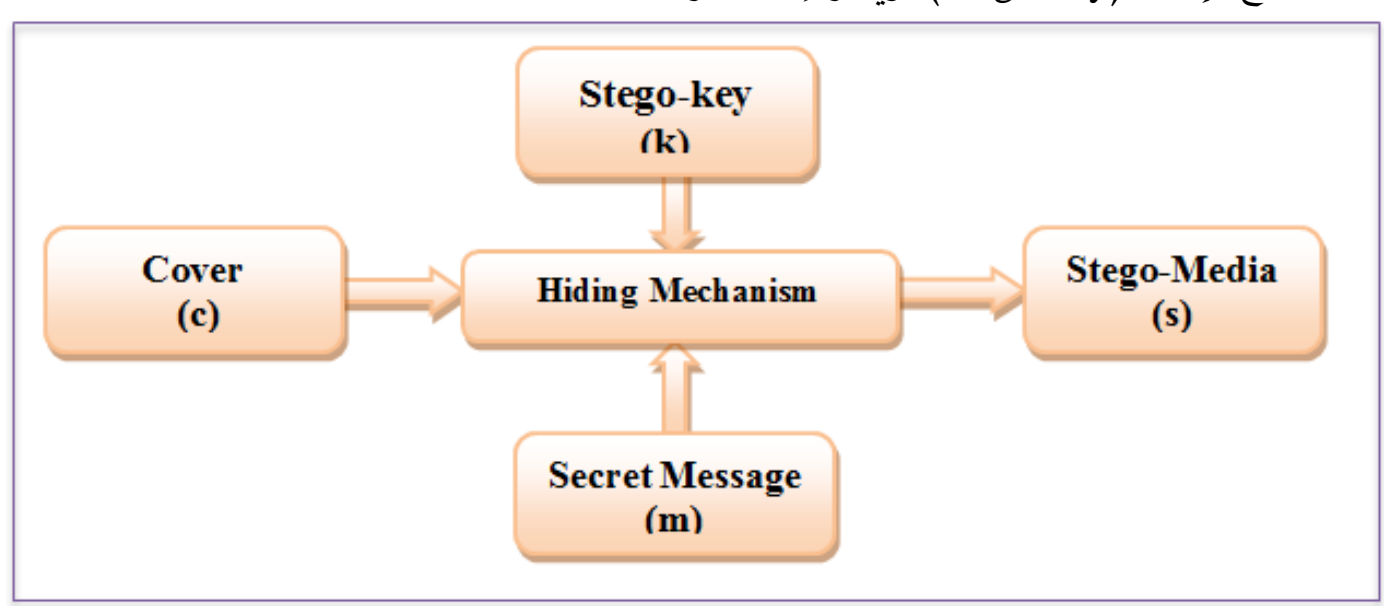

الثكل(1) عناصر الإخفاء

3. الحامض النووي الرايبي منقوص الأوكسجين Deoxyribonucleic Acid (DNA)

يمكن تعريفه بأنه التركيبة الكاملة للتعليمات الخاصة بتكوين الكائن الحي، ويحتوي على البصمات التي تحدد

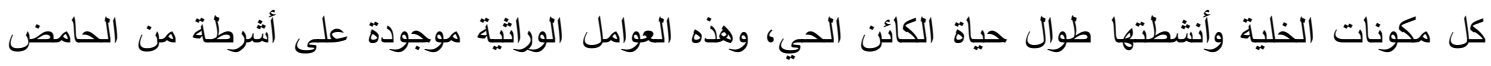


النووي (DNA) الحلزونية الثكل, فضلا عن جزيئات البروتين، وهما معا يكونان وحدات تسمى الكروموسومات، وعلى هذه الكروموسومات توجد المورثات أو الجينات (Genes) وهي التي تحدد كل صفات التئات الكائن الحي. والثكل

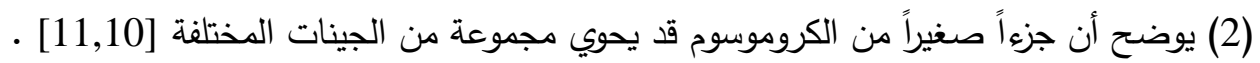

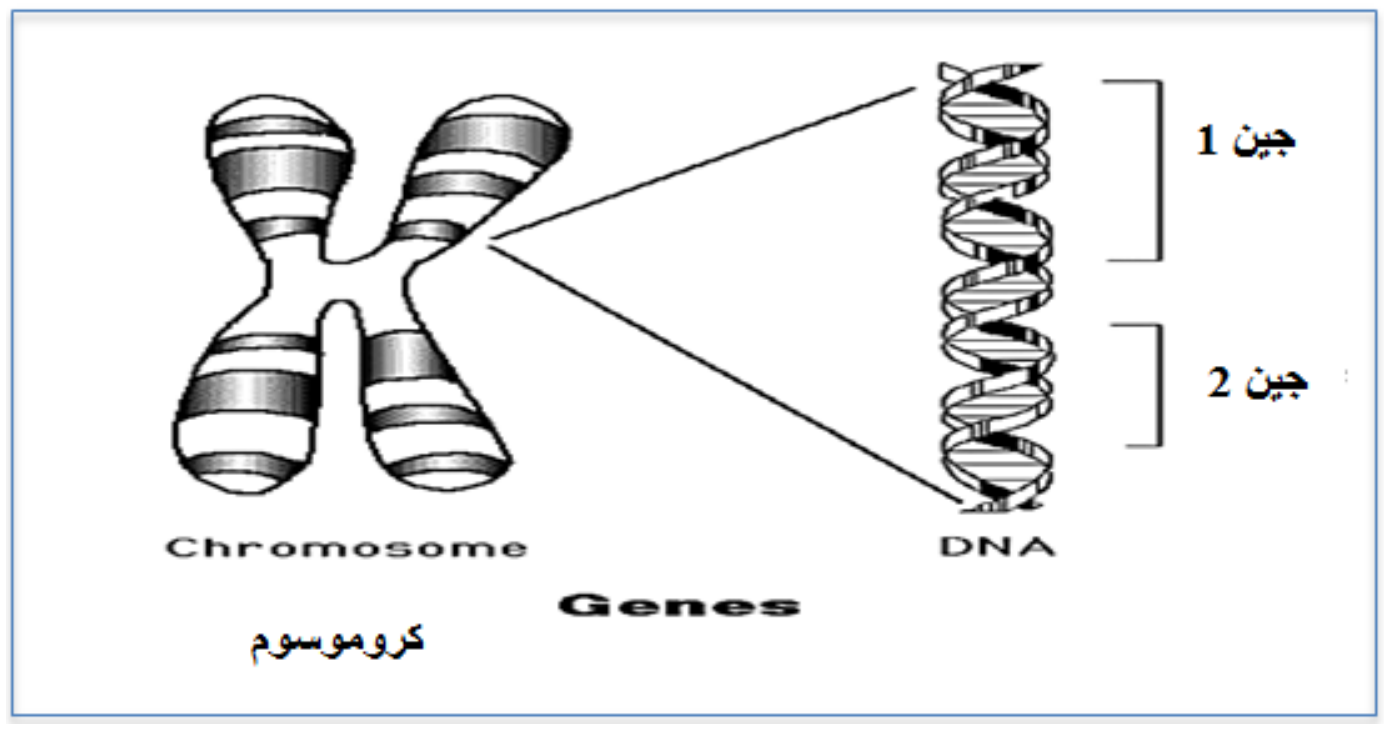

شكل (2) : يمثل مقطع للمادة الوراثية (DNA) والتي تتضمنها الجينات

إن الحامض النووي (DNA) يتكون من شريطين ملتفين على بعضهما بحيث يشبهان السلم الملتوي، وأنه

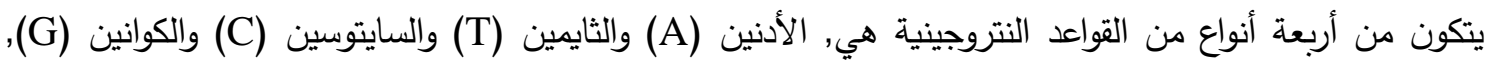

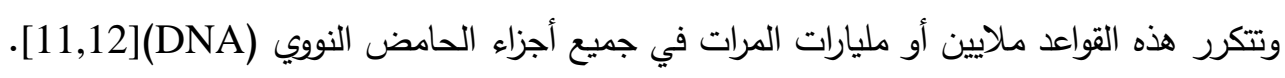

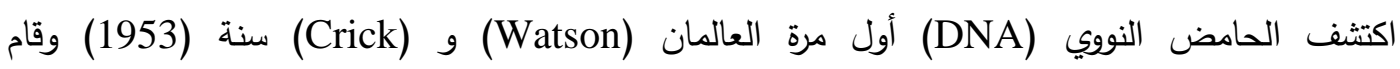
(Coenberg)

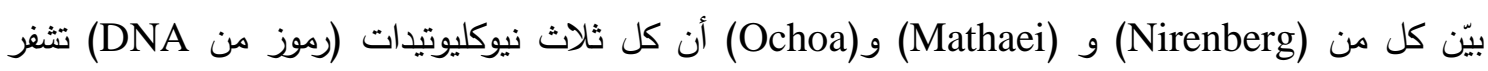
حامضاً أمينياً وحيداً من مجموع الحوامض الامينية. كما تم نشر تفاصيل لخوارزمية (Needleman-Wunsch) الخاصة بمقارنة السلاسل سنة (1970), وتبعها الإعلان عن إنثاء بنك بيانات البروتين (Protein Data Bank)

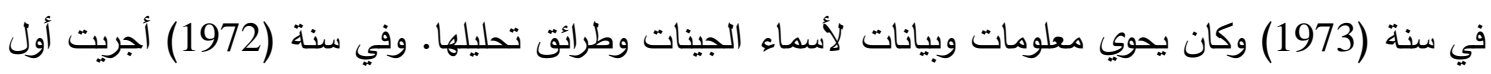
تجربة ناجحة لاستساخ الحامض النووي (DNA) في كاليفورنيا, وفي مطلع الثمانينات حصلت شركة (Cetus) الأمريكية على براءة إختراع لكونها استطاعت مضاعفة الحامض النووي باستخدام تقنية (PCR). (1990) تم إكمال مشروع الجينوم البشري الذي يعد ثروة علمية هائلة واكتثافاً رائعاً. أما في عام (2000) فقد أعلن العلماء بأنهم استطاعوا فك رموز الجينات الإنسانية, وجاء هذا نتيجة جهد فريق مؤلف من مجموعة تضم (1000) باحث, وأكد هؤلاء الباحثون أن هذا العمل سيحدث ثورة في علم التشخيص ومعالجة الأمراض وأنّ ترجمة

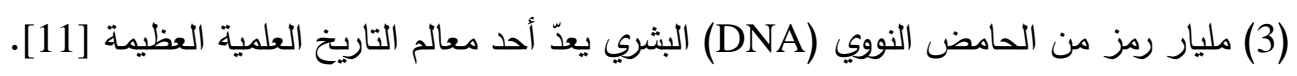

Bioinformatics المعلوماتية الحيوية

تُعرّف المعلوماتية الحيوية بأنها استخدام الحاسوب لمعالجة المعلومات الحيوية. وهو علم ركيزته الأساسية

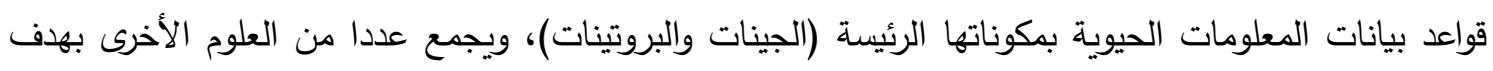


الاستفادة من هذه المعلومات كعلوم الرياضيات، والحاسوب، والإحصاء، والطب، والكيمياء. ويمكن أن نلخص

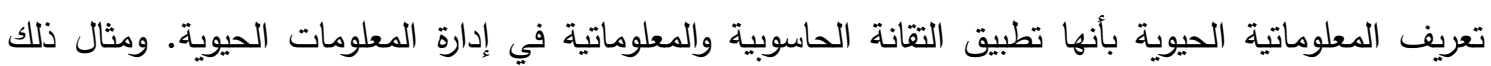
تحليل المعلومات الحيوية (الجينات والبروتينات) باستخدام الحاسوب والتقنيات الحاسوبية الحديثة [14,13] ـ بلدية

1.4. أهداف المعلوماتية الحيوية

$$
\text { للمعلوماتية الحيوية أهداف رئيسة ثلاثة هي }[14,13]
$$

1. تطوير تقنيات جديدة وبناء خوارزميات تساعد على تحصيل المعلومات من مجموعة ضخمة من البيانات.

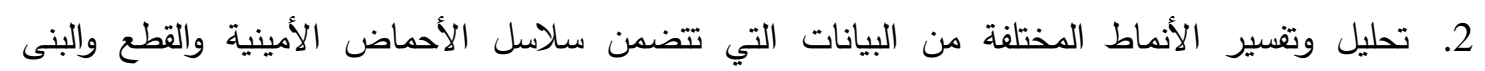
البروتينيّة. 3. تطوير وتتفيذ أدوات تساعد على إدارة فعّالة للأنماط المختلفة من المعلومات.

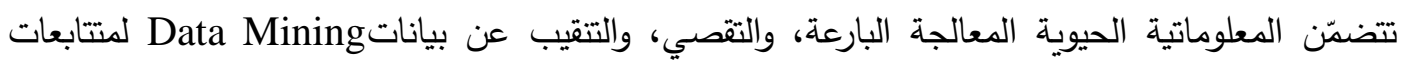
DNA

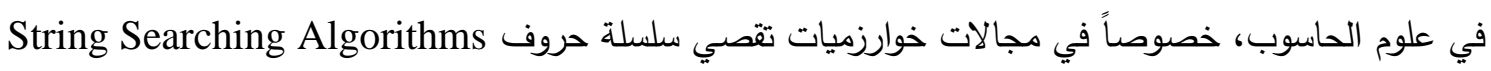

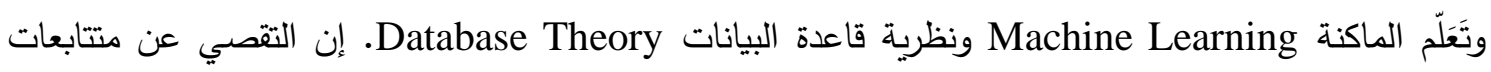
يُعنى بدراسة حدوثَ سلسلة حروف داخل سلسلة أكبر مِنْ الحروف، للتقصي عن متتابعات معيّنة مِن

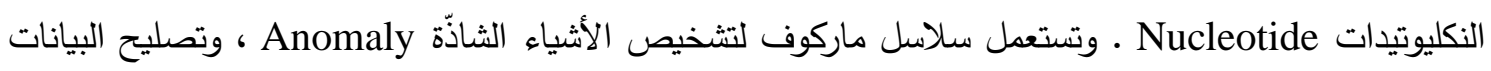
Repair Data

\section{5ata Base قواعد البيانات}

قواعد البيانات عبارة عن جداول او أرشفة الكترونية تستخدم لخزن وتتظيم البيانات بطريقة يمكن معها استرجاع المعلومات المطلوبة بسهولة باستخدام معايير بحث مختلفة .ان الهدف الرئيس من تطوير قواعد البيانات هو لتتظيم

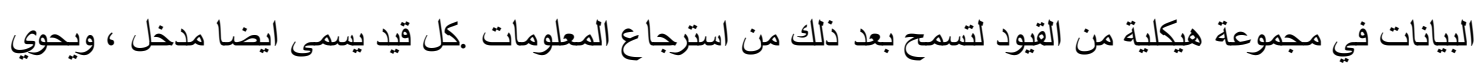

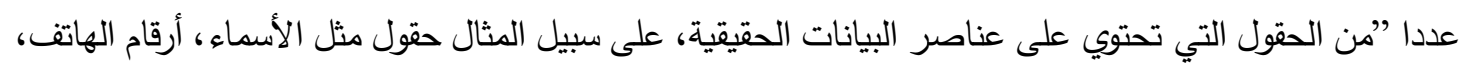

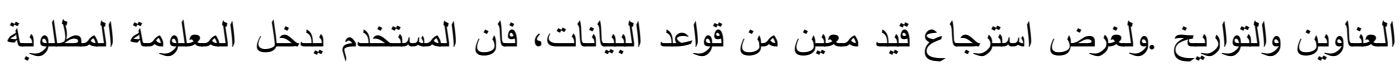

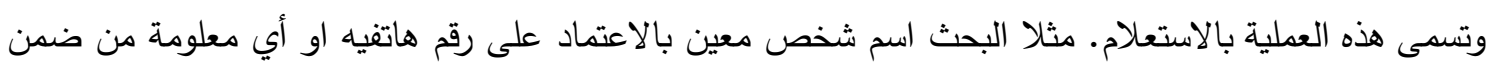

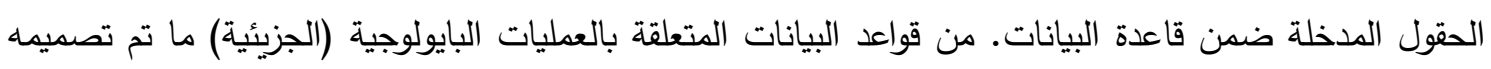
من قبل الحكومة الامريكية وهي قاعدة البيانات مقات (National Center for Biotechnology Information)

تحتوي هذا المركز على بنك الجينات(Gene Bank) التي تتضمن الالاف من تتابعات DNA و DNA

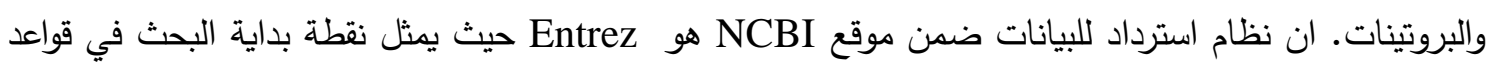

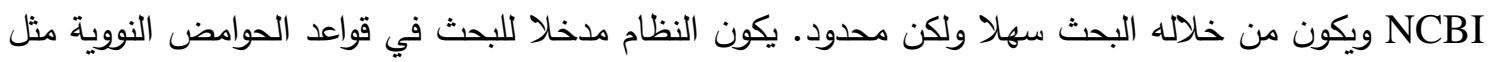

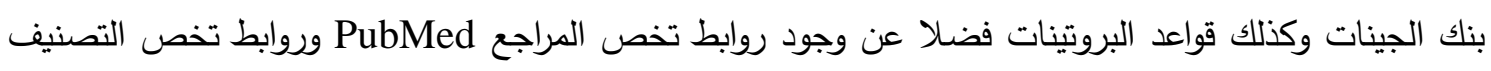

يتم عمل تحديث على بنك الجينات كل 18 شهر حيث يضاف اليه التتابعات الجديدة وتحذف بعض التتابعات المكررة [16] - معل تصل 
6estriction Enzymes انزيمات التقييد

لاشك ان كان لكل حي طرق دفاعية مختلفة تحميه من غارات الاعداد وهجوم المعتدين، فالبكتريا هي

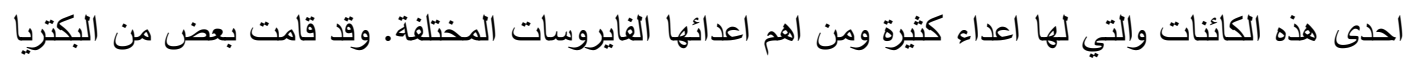
بإنتاج المقصات مهمتها تدمير الفايروسات. وتقوم هذه المقصات او ادوات القطع بقص الحامض الهض النووي

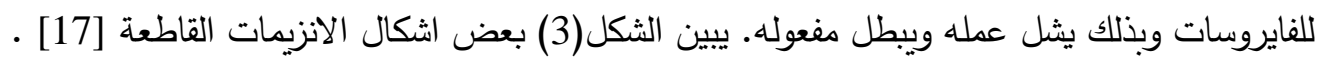

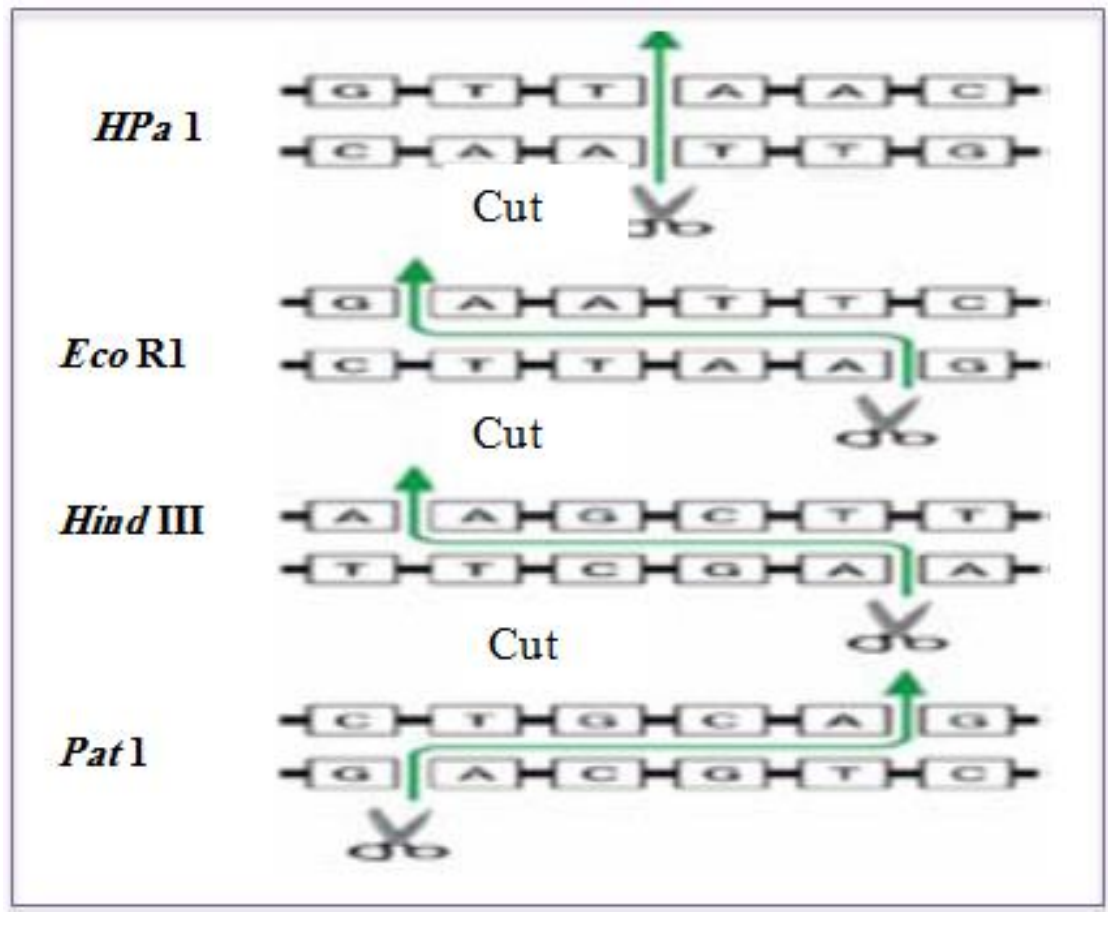

الثكل(3) امثلة لبعض الاتزيمات القاطعة

ان كل انزيم قاطع يعبر عن مقص خاص لقطع DNA في نقطع محددة، ويتعرف الانزيم القاطع على مكان القطع حسب تسلسل DNA للقطعة. فكل انزيم قاطع يقطع في تسلسل محد. فمثلا انزيم القطع Hpa1 يقطع عندما يجد 6 من القواعد النيتروجينية s بهذا التسلسل GTTTAAC بينما الانزيم القاطع EcoR1 يقطع عندما يجد 6 من القواعد النيتروجينية بهذا التسلسل GAATC. يوجد نوعين رئيسيين من المقصات، النوع الاول يقص

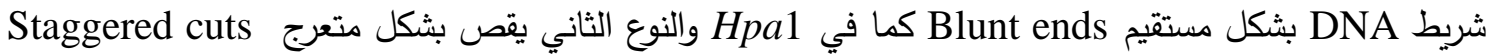
وبالتالي يجعل طرفي DNA المقطوع قابلة في اللصق قطعة غريبة من DNA فيها كما في EcoR1، والجدول(1) يوضح تسلسل مواقع القطع Recognition sites لبعض الانزيمات القاطعة الاتية[17]،وبما ان القواعد النيتروجينية للنهايات الناتئة متكاملة فإنها يمكن ان ترتبط مع بعضها مرة اخرى عن طريق الاواصر الهيدروجينية المتكون بين القواعد المتكاملة حيث ترتبط النهايات اللاصقة اولا عن طريق الاواصر الهيدروجينية المتكونة من القواعد المتكاملة مما يسهل عملية لحم الكسور بواسط انزيم لايجيز الدنا DNA Ligase لتكوين جزيئة دنا هجينة صنعية [18] • 
الجدول(1) تسلسل مواقع القطع Recognition sites لبعض الانزيمات القاطعة

\begin{tabular}{|c|c|c|}
\hline المقطع الذي يميزه القطع الانزيم القاطع| & المصدي| & BamHI \\
\hline GGATCC & Bacillus amyloliquefaciens H & EcoRI \\
\hline GAATTC & Escherichia coli RY13 & HaeIII \\
\hline GGCC & Haemophilus aegyptius & HindIII \\
\hline AAGCTT & Haemophilus nfluenza Rd & HpaI \\
\hline GTTAAC & Haemophilus parainfluenzae & HpaII \\
\hline CCGG & Haemophilus parainfluenzae & MboI \\
\hline GATC & Moraxella bovis & NotI \\
\hline GCGGCCGC & Nocardia otitidis-caviarum & SfiI \\
\hline GGCCNNNNNGGCC & Streptomyces fimbriatus &
\end{tabular}

بالنظر لاكتثاف اعدادا كبيرة من انزيمات التقيد كان لابد من ايجاد نظام تسمية على اساسه كل الانزيمات

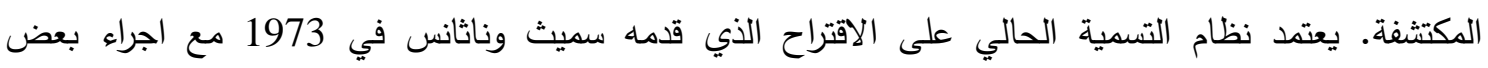
التغييرات البسيطة لتسهيل عملية التسمية ، تكون انزيمات التقييد حسب هذا النظام بأسماء مكونة من ثلاثة حروف تكتب بصورة مائلة او يوضع تحته خط. يدعى الانزيم التقييد المعزول من البكتيريا الهيموفلس بارا انفلونزا • [18] Hin ب influenza Hemophilus

\section{6. القطع المحدة Restriction Fragments}

عندما يضاف الانزيم القاطع الى محلول به شريط من DNA فانه يقطعه الى عدة قطع وليس قطعتين فقط، وكل قطعة مقطوعة بالإنزيم تسمى قطعة محددة، ويختلف الطول هذه القطع حسب المسافة بين كل قطعة واخر. ولكن يجب ان تكون كل قطعة محددة لها نفس الحجم في كل نوع من الكائنات الحية، وقد انشا العلماء خريطة ولة فئل تسمى خريطة القطع المحددة لكثير من الكائنات الحية حيث تبين هذه الخريطة مكان القطع ومحلها وطولها والتتابع

Suggested Method الخوارزمية المقترحة

\section{7. خوارزمية التضمين Embedding Algorithm}

المرسل: تتضمن خوارزمية بناء تتابع DNA الحاوية للرسالة السرية عدة خطوات :-

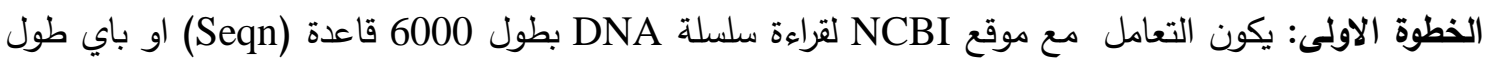
لجين يكون الاتفاق عليها مسبقاً، او بالإمكان توليدها باستخدام دالة التوليد العشوائي (Randseq)

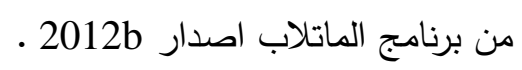

الخطوة الثانية: ادخال السلسلة (Seqn) الى دالة لإيجاد الانزيمات التي تقطع هذه السلسلة والقطع التي تقطعها واطوال كل قطعة واماكن القطع.

الخطوة الثالثة: استخدام القطع الناتجة (fragments) من الانزيمات لبناء جدول الرموز (symbol table) وذلك وكن بإعطاء كل قطعة ناتجة الى رمز معين (حروف، ارقام، حروف خاصة، (....).

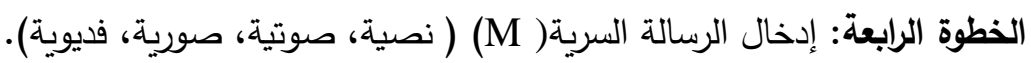

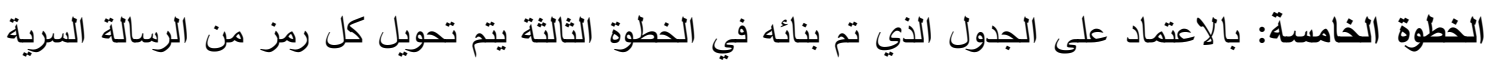

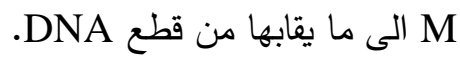


الخطوة السادسة: يتم ربط القطع الناتجة مع بعضها بأنزيم الرابط وبالأخير انتاج سلسلة Seqsec) DNA)

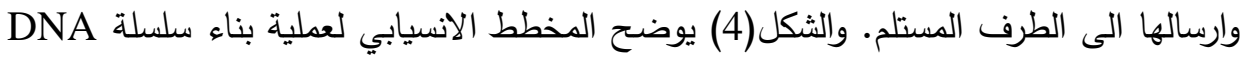
سري.

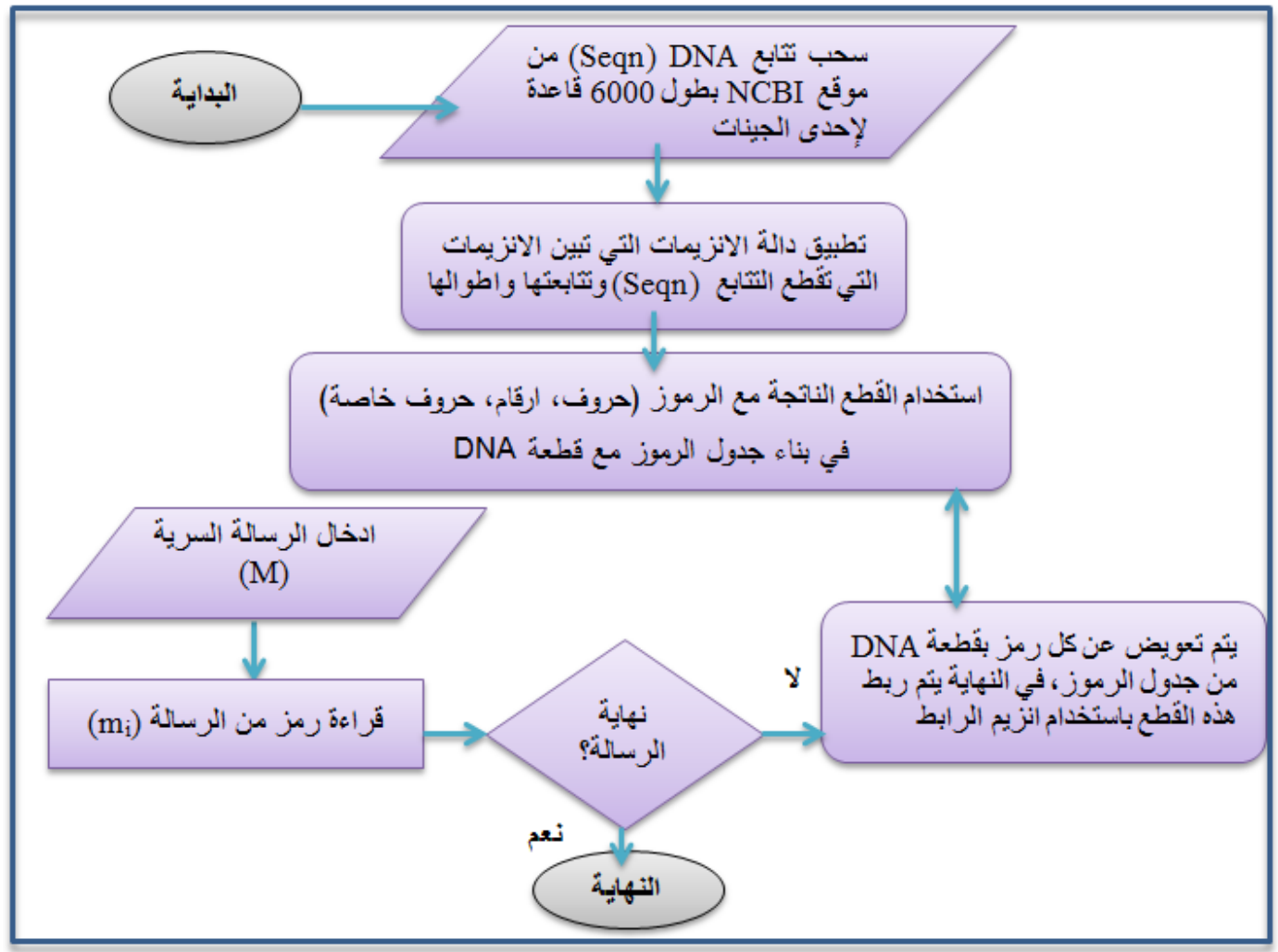

الثكل(4) المخطط الانسيابي لعملية بناء سلسلة DNA سري

Retrieving Algorithm 2.7 خوارزمية الاسترجاع

المستلم: تتضمن خوارزمية استرجاع الرسالة السرية من سلسلة DNA: بان يقوم المستلم بنفس خطوات الثلاثة

$$
\text { الاولى التي تم التطرق اليها عند المرسل. }
$$

الخطوة الاولى: يستخدم المستلم الانزيمات القاطعة لقطع سلسلة المستلمة (Seqsec) الىى قطع (Fragments). الخطوة الثانية: قراءة القطعة الناتجة من الخطوة السابقة ومقارنتها مع جدول الرموز وبناء string من الرموز •

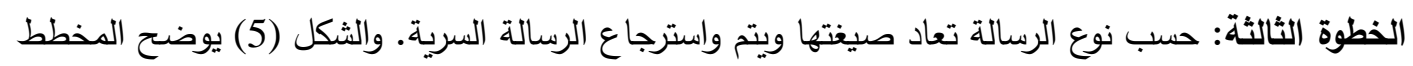

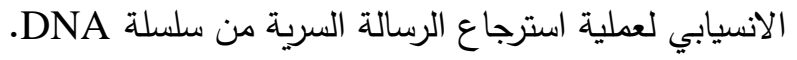




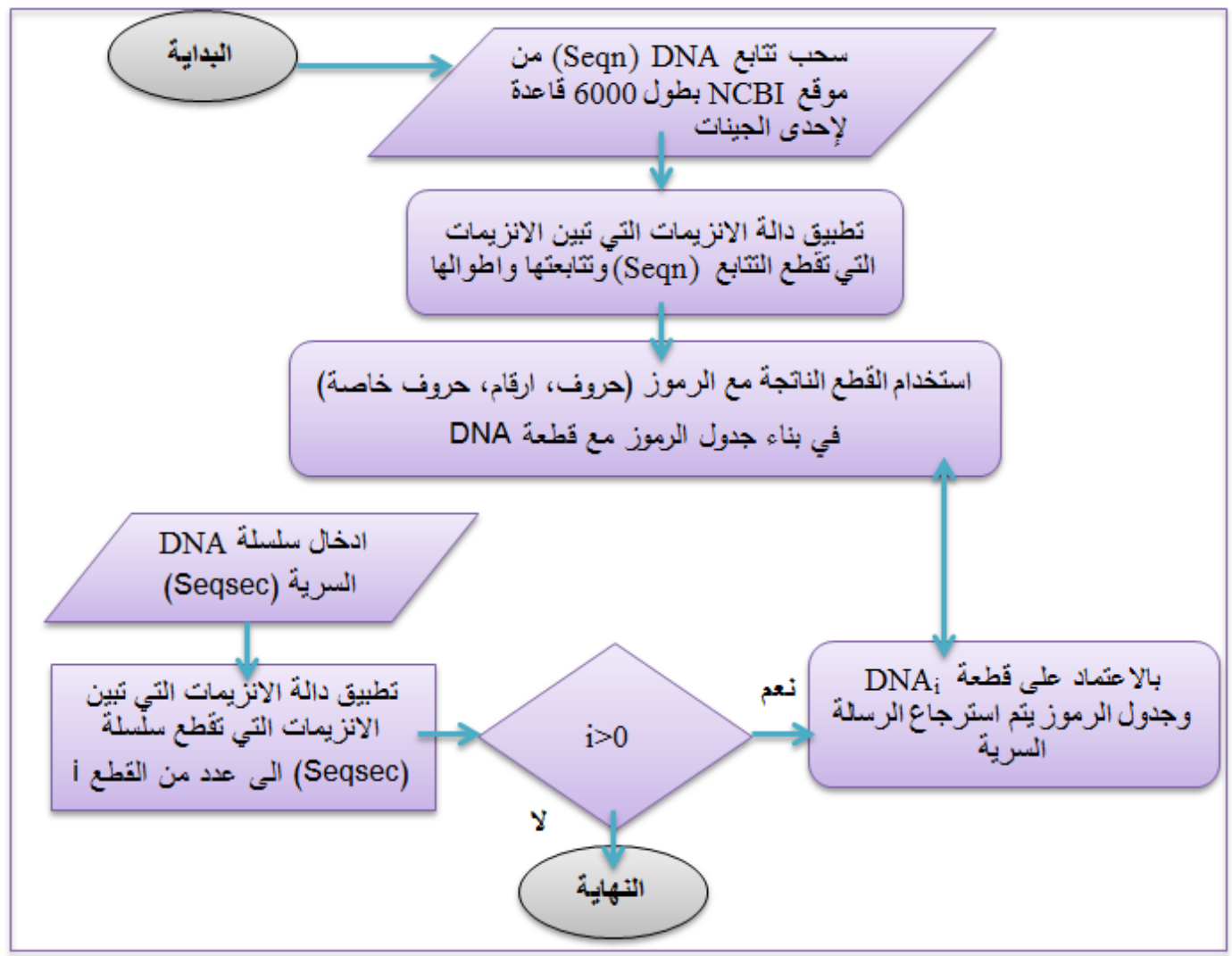

الثكل(5) يوضح المخطط الانسيابي لعملية استرجاع الرسالة السرية من سلسلة DNA

8. الاستنتاجات Conclusions

1. ان استخدام الطرق الحديثة وخاصة الدمج بين تقنيات علوم الحاسوب وعلم البايولوجي الجزيئي اعطت اهمية عالية في اخفاء المعلومات. (bioinformatics)

2. ان الطريقة المقترحة اعطت سرية عالية للرسالة السرية المرسلة لعدة اسباب منها:

ان استخدام الانزيمات القاطعة لترميز الرموز المختلفة اعطت احتمالية عالية جداً لكون وجود

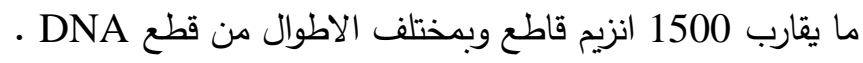

كون اطوال قطع DNA ومحتوياتها مختلفة فعند بناء سلسلة DNA السرية الحاوية على

الرسالة السرية يصعب استرجاع الرسالة منها من قبل المتطفل. 


\section{المصادر}

[1] Shejul, A. A. and Kulkarni, U. L., (2011), "A Secure Skin Tone Based Steganography using Wavelet Transform", International Journal of Computer Theory and Engineering, Vol. 3, No. 1, pp. 16-22.

[2] Reddy, T. CH. S., Prasad, D., and Reddy, B. V., (2012), "Protection through Oblivion: An Image Based Steganography “, Int. J. Computer Technology \& Applications, Vol. 3(1), pp. 420-424.

|القصاب، اسماء موفق،(2013)،"تقنية الكتابة المغطاة في الصور الكسورية باعتماد مجموعة جوليا"،

رسالة ماجستير، قسم علوم الحاسوب، كلية علوم الحاسوب والرياضيات، جامعة الموصل، العراق.

[4] Tejinderpal S., And Simpel J., (2011)," Image Steganography Using Mixed Channel Replacement ", International Journal Of Engineering Sciences Issn: 2229-6913 Issue, Vol. 4, pp. $62-70$.

فاضل، سميرة عباس،(2013)،" تتفيذ تقنيات الكتابة المغطاة على منصة لينكس"، رسالة ماجستير،

$$
\text { قسم علوم الحاسوب، كلية علوم الحاسوب والرياضيات، جامعة الموصل، العراق. }
$$

[6] Kriti S., and Pradeep K. S., (2010), “ A Variant of LSB Steganography for Hiding Images in Audio", International Journal of Computer Applications, Vol. 11, No.6, pp. $12-16$.

[7] M. Indra S. R., M. Purushotham R., K. and Subba R., ( 2012), “ Different Medias of Steganography- An Emerging Field of Network Security", International Journal of Computer Science and Information Technologies, Vol. 3 , No. 2 , pp. 3517-3522.

النعيمي، سماح فخري عزيز،(2011)،" تحليل الإخفاء بالاعتماد على تقنيتي آلة المتجه الداعم ومميز

فيشر الخطي في الصور الملونة"، رسالة ماجستير، قسم علوم الحاسوب، كلية علوم الحاسوب والرياضيات، جامعة الموصل، العراق.

الغريري، شهد عبد الرحمن حسّو، (2003)، " تصميم نظام حماية هجين و تطبيقه على النصوص"،

رسالة ماجستير، قسم علوم الحاسوب، كلية علوم الحاسوب والرياضيات، جامعة الموصل، العراق.

قاسم، عمر صابر (2009)." تطبيق التقنيات الذكائية في المعلوماتية الحيوية "، أطروحة دكتوراه،

كلية علوم الحاسوب والرياضيات، جامعة الموصل.

سواحل، وجدي عبد الفتاح ,(2001)، "استخدام الهندسة الوراثية في التحقيق الجنائي : أساليب

$$
\text { وتطبيقات", المركز القومي للبحوث , القاهرة. }
$$

[12] Calvino, M., Gomez, N. and Mingo, L.F.,(2007), "DNA Simulation of Genetic Algorithms: Fitness Computation”, International Journal,Information Theories \& Applications, Vol.14.

$$
\text { زماجستير، قسم فاطمة محمود حسن، (2011)،" استخدام النمذجة الماركوفية في المعلوماتية الحيوية"، رسالة }
$$


[14] Shoemaker, J.S. and Lin, S.M. (2005). "Methods of Microarray Data Analysis IV", Springer Science + Business Media, Inc.

الخياط ، باسل يونس ذنون وسليمان ، مثنى صبحي(2011) ،" التتبؤ عن الحالات المطرية في

مدينة الموصل"، بحث مقدم إلى المؤتمر العلمي الثالث / لعلوم الرياضيات ، 27 - 28 نيسان 2011 جامعة الزرقاء ، الاردن.

الخفاجي، زهرة محمود وابراهيم، علي عبد الحافظ ،(2012)،" المعلوماتية الحيوية “،ععهد الهندسة الوراثية والتتنيات الحيوية، جامعة بغداد، العراق.

عبيده، علي ابراهيم ومحمود، احمد عبدالفتاح،(2009)،" اساسيات التقنية الحيوية"، كلية الزراعة، سابا باشا، جامعة اسكندرية، مصر.

1البكري، غالب حمزة ، (1991) ، "مبادئ الهندسة الوراثية"، كلية العلوم ، جامعة البصرة، العراق. 